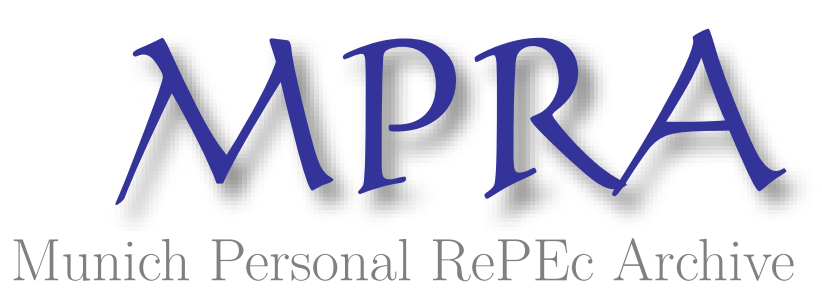

\title{
The Impacts of Rainfall Shocks on Birth Weight in Vietnam
}

Le, Kien and Nguyen, My

2019

Online at https://mpra.ub.uni-muenchen.de/109952/

MPRA Paper No. 109952, posted 29 Sep 2021 07:43 UTC 


\title{
The Impacts of Rainfall Shocks on Birth Weight in Vietnam
}

\author{
Kien Le \& My Nguyen ${ }^{\dagger}$
}

\begin{abstract}
This paper investigates the less discernible cost of rainfall shocks to birth weight outcomes within the context of Vietnam. Exploiting the variation across districts and conception months-years, we show that in-utero exposure to excessive and deficient rainfall shocks in the second trimester of pregnancy reduces child's weight at birth by 3.5 and $3.1 \%$, respectively. Besides, infants born to poor, rural, and low educated mothers are especially vulnerable to the adverse repercussions of rainfall shocks. Since poor infant health can leave persistent effects over the life cycle, the study calls for more efforts in intervention measures to mitigate the impacts of rainfall shocks. Additional attention should be given to children and women from disadvantaged backgrounds as this group is the most vulnerable.
\end{abstract}

JEL codes: I15, J13, O15, Q54

Keywords: Rainfall, Birth Weight, Intergenerational Effects, Vietnam

$\dagger$ Faculty of Economics and Public Management, Ho Chi Minh City Open University. Le: kien.le@ou.edu.vn. Nguyen (corresponding author): my.ngt@ou.edu.vn. 


\section{Introduction}

The variability of rainfall has been rising drastically across the globe due to climate change (Alexander, 2016; Myhre et al., 2019), thus affecting various socio-economic aspects. For example, rainfall shocks have been shown to be a reason for social unrest by inducing more conflict and crime (Miguel et al., 2004; Sekhri and Storeygard, 2014). Besides, rainfall shocks can also alter production and income, especially in the agricultural sector (Levine and Yang, 2006, Hidalgo et al., 2010; Bruckner and Ciccone, 2011, Vogel et al., 2019). Several studies further document the negative impacts of rainfall shocks on health and educational outcomes. In particular, children exposed to rainfall shocks have been shown to have lower nutrition statuses (Skoufias and Vinha, 2012; Jacoby et al., 2014) and primary school enrollment (Bjorkman-Nyqvist, 2013).

This paper examines how intrauterine exposure to rainfall shocks affects the birth weight outcomes of Vietnamese infants. By examining the intergenerational effects of rainfall shocks, our contribution to the literature is fourfold. First, we quantify the less discernible cost of rainfall shocks to human development of the future generation. Second, in exploring the relationship between fetal exposure to rainfall shocks and birth outcomes, we also link the epidemiology literature with climatic issues. Third, given that Vietnam is among the most affected countries by climate change, our estimated cost of rainfall variability to infant health could be particularly useful to Vietnamese policymakers. Fourth, given the lack of consensus about the relative importance of the intrauterine exposure timing, we further contribute to the literature by providing evidence for the importance of the second trimester.

The data used in this study come from the Vietnam Multiple Indicator Cluster Survey (MICS) and records for 70 weather stations across Vietnam from the Meteorological and Hydrological Administration of Vietnam. The MICS provides rich information on mothers and children as well as their geographic locations, while the climate records from the meteorological stations help us construct district-level rainfall data. In particular, employing the detailed spatial information and the child's birth date from these datasets, we compute our main explanatory 
variables based on the deviation of total rainfall in the three trimesters of pregnancy from the long-run local norms of total rainfall during those trimesters.

In terms of identification, we employ the difference-in-differences strategy across residential districts and conception months-years to quantify the effects of intrauterine exposure to rainfall shocks on birth weight outcomes. Put it differently, we compare the birth weight outcomes of children born to mothers experiencing rainfall shocks during pregnancy with those born to mothers unexposed to such events during pregnancy within the same residential district, relative to the analogous differences for those residing in other districts.

Within the difference-in-differences framework, we find that intrauterine exposure to excessive and deficient rainfall shocks in the second trimester of pregnancy decreases the child's weight at birth by 3.5 and $3.1 \%$ respectively. Besides, we detect heterogeneous impacts of rainfall shocks across different subgroups of the population. Particularly, infants from poor households seem to be more vulnerable to both excessive and deficient rainfall than those from non-poor households. Deficient rainfall tends to harm infants born to low education mothers and infants from rural areas, whereas the impacts of excessive rainfall do not seem to differ by maternal education or the locational status of infants. The presenting findings illustrate the vulnerability to rainfall shocks of children from disadvantaged backgrounds.

Our work provides meaningful implications for Vietnamese policymakers. The findings highlight the serious but less visible cost of rainfall shocks. In particular, the deteriorating impacts on birth weight outcomes underline the detrimental ramifications of rainfall shocks on long-term human development because poor infant health can leave persistent effects over the life cycle such as worsening educational attainment, lower labor market outcome, and higher vulnerability to diseases (Reyes and Manalich, 2005; Black et al., 2007; Oreopoulos et al., 2008; Xie et al., 2019). Therefore, the study calls for more efforts in intervention measures to mitigate the impacts of rainfall shocks. Additional attention should be given to children and women from disadvantaged backgrounds as this group is the most vulnerable. 
The paper proceeds as follows. Section 2 presents the literature review. Section 3 describes our data. Section 4 outlines the empirical methodology. Section 5 reports and discuss the estimating results.

\section{Literature Review}

Our empirical model to quantify the intergenerational effects of rainfall shocks is guided by the theoretical work of Corman et al. (1987). Specifically, their model suggests that infant health is one of the main arguments of the utility maximization problem facing parents during the prenatal period. Solving the model gives us infant health as a function of both maternal health and prenatal health inputs (e.g. medical services, vaccine, vitamin supplement, food). Regarding maternal health, rainfall shocks have been documented to induce violence against women (Vanden Eynde, 2018; Sekhri and Storeygard, 2014), force women to perform physically demanding tasks (Rao et al., 2003), engender psychological distress among pregnant women (Black et al., 2016), and make diseases such as malaria and diarrhea more prevalent (Umbers et al., 2011; Levy et al., 2016). Regarding prenatal health, adverse rainfall conditions have been shown to depress agricultural production (Levine and Yang, 2006, Vogel et al., 2019) and lower incomes (Hidalgo et al., 2010; Bruckner and Ciccone, 2011), which in turns worsens household ability to afford food supplies, medical services, vaccine, and vitamin supplement.

Our work can also be structured theoretically according to the UNICEF's conceptual framework in which infant health is driven by interconnected factors that are categorized into basic, underlying, and intermediate causes (UNICEF, 2014). First, with the basic causes (macro-level), rainfall shocks could induce instability in the socio-economic and political environment, thus putting a strain on pregnant women and impair the babies in utero (Vanden Eynde, 2018; Sekhri and Storeygard, 2014; Le and Nguyen, 2020a). Second, with the underlying causes (household-level), unfavorable rainfall conditions might force pregnant women to perform physically demanding tasks and engender their psychological distress, thus adversely affecting birth weight (Rao et al., 2003; Black et al., 2016). Third, with 
the immediate causes (individual-level), rainfall shocks could interfere with fetal growth by making dangerous diseases more prevalent (Umbers et al., 2011; Levy et al., 2016) and worsening nutrition supplies (Levine and Yang, 2006).

Empirically, this study can be related to two strands of studies. The first one explores the relationship between in-utero rainfall shocks and the health outcomes of children. Specifically, Cornwell and Inder (2015) and Le and Nguyen (2021) find that both abnormally dry and wet conditions during the prenatal period can worsen child nutrition in early childhood. Dimitrova and Bora (2020) and Randell et al. (2020) also detect a clear nutrition impact of fetal exposure to excessive rainfall on Indian and Ethiopian children. The second branch of empirical studies which our study also fits into explores the relationship between in-utero shocks and infant health. One type of shock that could leave serious implications on infant health is violence. Particularly, women experiencing armed conflict, terrorism, or uprising tend to give birth to lightweight infants (Mansour and Rees, 2012; Lee, 2014; QuintanaDomeque and Rodenas-Serrano, 2017; Brown, 2020; Le and Nguyen, 2020a). Natural disaster is another example of shock that could deteriorate newborn health (Simeonova, 2011; Liu et al., 2015). Besides, there is evidence that infants born to women who experienced heat shock during pregnancy are more likely to weigh less at birth (Deschenes et al., 2009; Molina and Saldarriaga, 2017). Furthermore, fetal exposure to nutritional deprivation, power outage, and pandemic is also associated with worse birth outcomes (Almond and Mazumder, 2011; Burlando, 2014; Dorelien, 2019).

Despite the consensus on the impacts of in-utero exposure to negative shocks on infant health, the relative importance of the exposure timing is still the subject of debate in the literature. In particular, multiple studies document that the impacts are concentrated in the first trimester (e.g., Mansour and Rees, 2012; Molina and Saldarriaga, 2017; Brown, 2020). While there is evidence that it is the shock happening during the second trimester that produces the negative impacts on birth outcomes (e.g., Simeonova, 2011; Lee, 2014; Liu et al., 2015), a number of studies point to the relative importance of the third trimester (e.g., 
Dorelien, 2019; Randell et al., 2020).

\section{Data}

Data on Mothers and Children - Child's weight at birth and demographic characteristics are drawn from the Vietnam Multiple Indicator Cluster Survey (MICS). The MICS program is carried out by the Vietnam General Statistics Office with technical and financial support from the United Nations Children's Fund (UNICEF). This is a rich dataset focusing on key indicators to monitor progress towards the Millennium Development Goals (MDGs) and other internationally agreed upon commitments. ${ }^{1}$ Currently, there are four waves that are publicly available (MICS2, MICS3, MICS4, MICS5).

We mainly rely on the Woman's Questionnaire which focuses on women of reproductive age. These women were surveyed on their demographic backgrounds, fertility, birth date, and birth weight of their children, among others. In order to combine this dataset with the rainfall data, we must have the geographic locations of the children and mothers. Hence, we utilize the MICS waves where information on residential districts is available. Consequently, we can only utilize MICS3 and MICS4 to construct the estimation sample because the other ones do not provide information on either birth weight or specific residential areas.

Information on the child's weight at birth is collected from the weight as recorded on a health card or the mother's recall. Approximately 87 and 93\% of children in MICS3 and MICS4 have their birth weight collected from a health card, which strengthens the accuracy of our birth weight measure and reduces the likelihood of recall bias. Since there is still a small fraction of children having their birth weight collected from their mother's recall, we control for child's age in months in all of our regressions to account for the amount of time elapsed from birth. Furthermore, we conduct a correlation test to see if mother and child characteristics are correlated with how birth weight information is collected. To do so, we construct an indicator Weight from Card that takes the value of one if birth weight is

\footnotetext{
1 Additional information can be found at www.gso.gov.vn and mics.unicef.org.
} 
collected from the weight as recorded on a health card, and zero otherwise. We then regress the indicator Weight from Card on birth weight measures (in log form and in normal form), child variables (gender, age in months, whether the child lives in urban areas), and mother variables (age at birth, age at first birth, marital status, education, wealth index), with and without additional covariate. The results reported in Table A1 and A2 suggest that how birth weight information is collected is uncorrelated with mother and child characteristics. In other words, our study is unlikely to suffer from selection bias.

Data on Rainfall - We collect rainfall data from the Meteorological and Hydrological Administration of Vietnam, which includes rainfall records of 70 land-based stations across Vietnam. $^{2}$ For each station, the data provide the geographic location (a pair of latitude and longitude) and monthly rainfall information. Next, we allocate rainfall data to each district according to the records of the station closest to the district centroid.

We then identify rainfall shocks based on the deviation of rainfall from the long-run local norm. First, for each trimester of pregnancy, we compute in-utero rainfall deviation as the difference between total rainfall and the long-run average of total rainfall, then divided by the long-run standard deviation of total rainfall in the child's district during the corresponding three months of pregnancy. The three-month long-run average and standard deviation are calculated from the entire data period (2002-2012) for each district. For example, for a child in utero between November 2005 and July 2006, rainfall deviation in his/her first trimester from November to January $\left(R_{N o v-J a n}^{1}\right)$ is given by,

$$
R_{\text {Nov-Jan }}^{1}=\frac{T R_{\text {Nov-Jan }}^{1}-L R T R_{\text {Nov-Jan }}^{1}}{L R S D_{\text {Nov-Jan }}^{1}}
$$

where the total rainfall in these three months of the first trimester $\left(T R_{N o v-J a n}^{1}\right)$ is the sum of monthly total rainfall from November 2005 to January 2006 in the child's residential district. The three-month long-run total rainfall $\left(L R T R_{N o v-J a n}^{1}\right)$ and long-run standard deviation of

${ }^{2}$ Figure A1 in the Appendix illustrates the distribution of rainfall stations (black dots) and districts (gray polygons) across Vietnam. 
rainfall $\left(L R S D_{N o v-J a n}^{1}\right)$ are the 2002-2012 mean and standard deviation of total rainfall for November through January in the child's residential district, respectively.

Our objective is to examine both excessive and deficient shocks of rainfall. Thus, following the standard in the literature, for each trimester, we construct two explanatory variables indicating whether there exist excessive or deficient rainfall shocks of one standard deviation above or below the local norm in the corresponding trimester. In particular, for trimester $j$, the variable Excessive Rainfall $\left(E R^{j}\right)$ takes the value of one if the rainfall deviation $\left(R^{j}\right)$ calculated from equation (1) is greater than one, and zero otherwise. Analogously, Deficient Rainfall $\left(D R^{j}\right)$ takes the value of one if the rainfall deviation $\left(R^{j}\right)$ is less than negative one, and zero otherwise. Back to our example in the previous paragraph, for a child in utero between November 2005 and July 2006, Excessive Rainfall and Deficient Rainfall in his/her first trimester are given by,

$$
\begin{aligned}
& E R_{\text {Nov-Jan }}^{1}= \begin{cases}1 & \text { if } \quad R_{\text {Nov-Jan }}^{1}>1 \\
0 & \text { otherwise }\end{cases} \\
& D R_{\text {Nov-Jan }}^{1}= \begin{cases}1 & \text { if } \quad R_{\text {Nov-Jan }}^{1}<-1 \\
0 & \text { otherwise }\end{cases}
\end{aligned}
$$

where $E R_{N o v-J a n}^{1}$ and $D R_{N o v-J a n}^{1}$ are in-utero excess and lack of rainfall indicators during the first trimester for the child conceived in November 2005. The procedure is analogous for the second $\left(E R_{F e b-A p r}^{2}, D R_{F e b-A p r}^{2}\right)$ and the third trimester variables $\left(E R_{M a y-J u l}^{2}, D R_{M a y-J u l}^{2}\right)$. Summary Statistics - Our sample consists of 1,961 children born between 2004 and 2011. The descriptive statistics for the main variables are reported in Table 1 for the entire sample. As shown in Column 1, the average birth weight is almost 3.1 kilograms (kg). Approximately $52 \%$ of children are male and $37 \%$ of children live in urban areas. The mean age of children in our sample is 12 months. Mothers were 28 years old on average when they gave birth and were 23 years old on average at the time of their first birth. The majority of mothers (99\%) 
Table 1: Summary Statistics

\begin{tabular}{lccc}
\hline & Mean & Standard Deviation & Observation \\
\cline { 2 - 4 } & $(1)$ & $(2)$ & $(3)$ \\
\hline Children Variables & 3.093 & 0.446 & 1,961 \\
Birth Weight (kg) & 1.118 & 0.158 & 1,961 \\
Log Birth Weight & 0.515 & 0.499 & 1,961 \\
Being Male & 12.16 & 6.849 & 1,961 \\
Age in Months & 0.369 & 0.483 & 1,961 \\
Residing in Urban Area & & & \\
Mother Variables & 28.06 & 5.562 & 1,961 \\
Age at Birth & 23.31 & 3.957 & 1,961 \\
Age at First Birth & 0.988 & 0.108 & 1,961 \\
Currently Married & 0.207 & 0.405 & 1,961 \\
High School Graduate & 3.170 & 1.409 & \\
Wealth Index & & & 1,961 \\
Main Explanatory Variables & 0.161 & 0.367 & 1,961 \\
Trimester 1 - Excessive Rainfall & 0.135 & 0.342 & 1,961 \\
Trimester 2 - Excessive Rainfall & 0.170 & 0.376 & 1,961 \\
Trimester 3 - Excessive Rainfall & 0.145 & 0.353 & 1,961 \\
Trimester 1 - Deficient Rainfall & 0.188 & 0.391 & 1,961 \\
Trimester 2 - Deficient Rainfall & 0.179 & 0.384 & \\
Trimester 3 - Deficient Rainfall & & & \\
\hline \hline
\end{tabular}

Note: Birth weight is measured in kilograms $(\mathrm{kg})$. Being Male and Residing in Urban Area are indicators taking a value of one if the child is male and residing in the urban area, respectively. Age at Birth refers to the mother's age when giving birth to the child. Age at First Birth refers to the mother's age when delivering her first birth. Currently Married and High School Graduate are indicators taking a value of one if the mother is currently married and holds a high school diploma, respectively. Wealth Index categorizes households into five wealth quintiles.

are married and only $21 \%$ of mothers completed at least high school. The mean value of the wealth index is roughly 3.2. Turning to our main explanatory variables, approximately $16.1,13.5$, and $17 \%$ of children were exposed to excessive rainfall during the first, second, and third trimesters, respectively. The proportions exposed to deficient rainfall during the first, second, and third trimesters are 14.5, 18.8, and 17.9\%, respectively.

\section{Empirical Methodology}

To estimate the effects of exposure to rainfall shocks during pregnancy on birth weight outcomes and tackle the lack of consensus on the relative importance of the exposure timing, 
we employ the following difference-in-differences (DiD) model,

$$
Y_{i s t}=\beta_{0}+\sum_{j=1}^{3} \beta_{E}^{j} E R_{s t}^{j}+\sum_{j=1}^{3} \beta_{D}^{j} D R_{s t}^{j}+X_{i s t}^{\prime} \Omega+\lambda_{s}+\delta_{t}+\lambda_{s} \times t+\epsilon_{i s t}
$$

where the subscript $i, s$, and $t$ correspond to child, residential district, and conception month-year. The superscript $j$ stands for trimester. The outcome variable, $Y_{i s t}$, is the child's weight and the log of weight at birth.

As we want to explore exposure to rainfall shocks in which stage of pregnancy affects birth weight, we have trimester-specific exposure indicators as the key explanatory variables. In particular, the variables $\left\{E R_{s t}^{1}, E R_{s t}^{2}, E R_{s t}^{3}\right\}$ take the value of one if the mother is exposed to excessive rainfall shocks in her residential district during the first, second, and third trimesters of pregnancy respectively, and zero otherwise. Analogously, the variables $\left\{D R_{s t}^{1}, D R_{s t}^{2}, D R_{s t}^{3}\right\}$ equal one if the mother experiences deficient rainfall shocks in her residential district during the corresponding trimesters of pregnancy, and zero otherwise.

Vector $X_{i s t}^{\prime}$ denotes child and mother characteristics including child's gender, child's age in months, child's age in months squared, locational status (urban/rural), mother's age at birth, age at birth squared, age at first birth, age at first birth squared, marital status, educational attainment, and wealth index. The terms $\lambda_{s}$ and $\delta_{t}$ represent district and conception monthyear fixed effects, respectively. We also denote by $\lambda_{s} \times t$ the district-specific birth cohort trend at the conception month-year level. Finally, $\epsilon_{i s t}$ stands for the idiosyncratic error term. Standard errors throughout the paper are clustered at the residential district level since the source of variation is within and across districts.

Our coefficients of interest are $\left\{\beta_{E}^{1}, \beta_{E}^{2}, \beta_{E}^{3}\right\}$ and $\left\{\beta_{D}^{1}, \beta_{D}^{2}, \beta_{D}^{3}\right\}$ which capture the impacts on birth weight outcomes of excessive and deficient rainfall shocks in each of the pregnancy trimesters. In this DiD framework, we compare the birth weight of children born to mothers exposed to rainfall shocks with those born to mothers unexposed to such events during pregnancy within the same district, relative to the analogous differences for mothers residing 
in other districts. The treatment group includes mothers exposed to rainfall shocks during any trimester of pregnancy, and the control group consists of: (i) mothers subject to rainfall shocks prior to conception, (ii) mothers exposed to rainfall shocks after birth delivery, and (iii) mothers unexposed to rainfall shocks at all. Since previous studies argue that one control group might be more preferable than the others (Persson and Rossin-Slater, 2018; Matsumoto, 2018; Currie et al., 2019), we later conduct robustness checks and find that our results are insensitive to different categorizations of the control group.

\section{Results}

\subsection{Main Results}

The quantified relationship between rainfall shocks and birth weight outcomes are presented in Table 2. Results on the log of birth weight and birth weight in normal form (in kilograms) are provided in Columns 1-3 and Columns 4-6, respectively. We report the estimates for the most parsimonious specification in Columns 1 and 4 where only district effects are controlled for. Next, In Columns 2 and 5, we include into our regressions a set of mother characteristics such as mother's age at birth, age at birth squared, age at first birth, age at first birth squared, marital status, educational attainment, and wealth level. Finally, Columns 3 and 6 provide our most extensive specification where we introduce to the previous specification a set of child characteristics such as child's gender, child's age in months, child's age in months squared, locational status (urban/rural), district-specific birth cohort trend, and conception month-year fixed effects.

According to our most parsimonious specifications, second-trimester exposure to excessive and deficient rainfall shocks decreases child's weight at birth by 3.4 and 3.6\% (Column 1) or by 0.095 and 0.104 kilograms, respectively (Column 4). Accounting for mother characteristics does not substantially change our estimates (Columns 2 and 5). Finally, the results from

our most extensive specifications suggest that exposure to excessive and deficient rainfall shocks during the second trimester in utero decreases the child's weight at birth by 3.5 and 
Table 2: Impacts of Rainfall Shocks on Birth Weight Outcomes

\begin{tabular}{|c|c|c|c|c|c|c|}
\hline & \multicolumn{3}{|c|}{$\mathrm{Y}=\log$ Birth Weight } & \multicolumn{3}{|c|}{$\mathrm{Y}=$ Birth Weight } \\
\hline & (1) & $(2)$ & (3) & (4) & $(5)$ & (6) \\
\hline Trimester 1 - Excessive Rainfall & $\begin{array}{c}0.017 \\
(0.012)\end{array}$ & $\begin{array}{c}0.015 \\
(0.013)\end{array}$ & $\begin{array}{c}0.016 \\
(0.014)\end{array}$ & $\begin{array}{c}0.058 \\
(0.040)\end{array}$ & $\begin{array}{c}0.050 \\
(0.041)\end{array}$ & $\begin{array}{c}0.055 \\
(0.044)\end{array}$ \\
\hline Trimester 2 - Excessive Rainfall & $\begin{array}{c}-0.034^{* *} \\
(0.016)\end{array}$ & $\begin{array}{c}-0.035^{* *} \\
(0.015)\end{array}$ & $\begin{array}{c}-0.035^{* *} \\
(0.015)\end{array}$ & $\begin{array}{c}-0.095^{* *} \\
(0.046)\end{array}$ & $\begin{array}{c}-0.098^{* *} \\
(0.045)\end{array}$ & $\begin{array}{c}-0.097^{* *} \\
(0.045)\end{array}$ \\
\hline Trimester 3 - Excessive Rainfall & $\begin{array}{c}0.004 \\
(0.012)\end{array}$ & $\begin{array}{c}0.007 \\
(0.012)\end{array}$ & $\begin{array}{c}0.009 \\
(0.012)\end{array}$ & $\begin{array}{c}0.016 \\
(0.038)\end{array}$ & $\begin{array}{c}0.027 \\
(0.036)\end{array}$ & $\begin{array}{c}0.032 \\
(0.035)\end{array}$ \\
\hline Trimester 1 - Deficient Rainfall & $\begin{array}{c}0.018 \\
(0.016)\end{array}$ & $\begin{array}{c}0.013 \\
(0.011)\end{array}$ & $\begin{array}{c}0.016 \\
(0.012)\end{array}$ & $\begin{array}{c}0.055 \\
(0.041)\end{array}$ & $\begin{array}{c}0.037 \\
(0.034)\end{array}$ & $\begin{array}{c}0.045 \\
(0.036)\end{array}$ \\
\hline Trimester 2 - Deficient Rainfall & $\begin{array}{c}-0.036^{* * *} \\
(0.013)\end{array}$ & $\begin{array}{c}-0.034^{* * *} \\
(0.013)\end{array}$ & $\begin{array}{c}-0.031^{* *} \\
(0.013)\end{array}$ & $\begin{array}{c}-0.104^{* * *} \\
(0.037)\end{array}$ & $\begin{array}{c}-0.097^{* * *} \\
(0.038)\end{array}$ & $\begin{array}{c}-0.087^{* *} \\
(0.040)\end{array}$ \\
\hline Trimester 3 - Deficient Rainfall & $\begin{array}{c}0.002 \\
(0.010)\end{array}$ & $\begin{array}{c}0.004 \\
(0.010)\end{array}$ & $\begin{array}{c}0.005 \\
(0.009)\end{array}$ & $\begin{array}{c}0.013 \\
(0.035)\end{array}$ & $\begin{array}{c}0.020 \\
(0.034)\end{array}$ & $\begin{array}{c}0.024 \\
(0.031)\end{array}$ \\
\hline Observations & 1,961 & 1,961 & 1,961 & 1,961 & 1,961 & 1,961 \\
\hline Child Characteristics & & & $\checkmark$ & $\cdot$ & & $\checkmark$ \\
\hline Mother Characteristics & . & $\checkmark$ & $\checkmark$ & . & $\checkmark$ & $\checkmark$ \\
\hline District Fixed Effects & $\checkmark$ & $\checkmark$ & $\checkmark$ & $\checkmark$ & $\checkmark$ & $\checkmark$ \\
\hline
\end{tabular}

Note: ${ }^{*} p<0.1,{ }^{* *} p<0.05,{ }^{* * *} p<0.01$. Each column represents coefficients in a separate regression. Dependent variables are the child's weight at birth in log form (Columns 1-3) and normal form in kilogram (Columns 4-6). Mother Characteristics include mother's age at birth, age at birth squared, age at first birth, age at first birth squared, marital status, educational attainment, and wealth level. Child Characteristics include child's gender, child's age in months, child's age in months squared, locational status (urban/rural), district-specific birth cohort trend, and conception month-year fixed effects. Robust standard errors are clustered at the district level.

$3.1 \%$ (Columns 3) or reduces infant birth weight by 0.097 and 0.087 kilograms (Columns 6). However, rainfall shocks in the first and the third trimesters do not seem to affect birth outcomes as the point estimates are statistically and economically insignificant. Overall, the results in Table 2 highlight the detrimental consequences of excessive rainfall and deficient rainfall relative to the long-run local average during gestation on child's weight at birth.

\subsection{Heterogeneity Analyses}

We proceed to explore the heterogeneous impacts of in-utero exposure to rainfall shocks on birth weight outcomes along the lines of family wealth, locational status, and mother educational attainment, using the most extensive specifications (similar to Columns 3 and 6 of Table 2). The quantified relationships are reported in Table 3. Dependent variables are the child's birth weight in log form (Panel A) and normal form (Panel B). Each column 
represents a separate regression, and the column headings indicate subgroup levels.

We first investigate whether the impacts of in-utero exposure to rainfall shocks differ by household wealth (Columns 1 and 2, Table 3). Poor households are categorized as households in the bottom and second quintiles of the wealth distribution. Likewise, non-poor households are households in the remaining upper three quintiles. We find that exposure to excessive rainfall during the second trimester imposes inimical repercussions on both birth weight measures of children from poor households (Column 1). The impacts are around 77-79\% smaller in magnitude and statistically insignificant for children from non-poor households (Column 2). Exposure to deficient rainfall during the second trimester also adversely affects birth weight of children from poor households and the impacts are 76-81\% weaker among children from non-poor households. Consistent with the results in Section 5.1, there is no evidence on the effects of rainfall shock exposure in the first and the third trimesters. Collectively, the results in Columns 1 and 2 suggest that a more advantaged socioeconomic background can offset the adverse impacts of rainfall shocks during gestation.

In Columns 3 and 4, we proceed to explore potentially heterogeneous impacts of rainfall shocks by place of residence. In other words, we want to examine if rainfall shocks affect rural and urban infants differentially. Evident from Columns 3 and 4, the impacts of excessive rainfall during the second trimester of pregnancy on birth weight do not seem to vastly differ between children from urban areas and those from rural areas. As for deficient rainfall, the effects are substantially larger for infants in rural areas than infants in urban areas. It is possible that rural infants might be more vulnerable to deficient rainfall compared to urban infants.

In Columns 5 and 6, we examine if the impacts of in-utero exposure to rainfall shocks differ between infants born to low education mothers and those born to high education mothers. Low education mothers are mothers who did not complete high school. High education mothers are those with at least a high school diploma. We find that second trimester exposure to excessive rainfall lowers the weight at birth of children born to low education mothers and 
Table 3: Heterogeneity by Wealth, Residential Area, and Mother Education

\begin{tabular}{lcccccc}
\hline & $\begin{array}{c}\text { Poor } \\
\text { Households }\end{array}$ & $\begin{array}{c}\text { Non-poor } \\
\text { Households }\end{array}$ & $\begin{array}{c}\text { Rural } \\
\text { Area }\end{array}$ & $\begin{array}{c}\text { Urban } \\
\text { Area }\end{array}$ & $\begin{array}{c}\text { Low } \\
\text { Education }\end{array}$ & $\begin{array}{c}\text { High } \\
\text { Education }\end{array}$ \\
\cline { 2 - 7 } & $(1)$ & $(2)$ & $(3)$ & $(4)$ & $(5)$ & $(6)$ \\
\hline Panel A: Y = Log Birth Weight & & & & & & \\
Trimester 1 - Excessive Rainfall & 0.024 & 0.011 & 0.019 & -0.023 & 0.027 & -0.036 \\
& $(0.026)$ & $(0.019)$ & $(0.017)$ & $(0.021)$ & $(0.017)$ & $(0.036)$ \\
Trimester 2 - Excessive Rainfall & $-0.078^{* * *}$ & -0.018 & $-0.047^{* *}$ & -0.037 & $-0.031^{* *}$ & -0.036 \\
& $(0.024)$ & $(0.018)$ & $(0.021)$ & $(0.034)$ & $(0.014)$ & $(0.047)$ \\
Trimester 3 - Excessive Rainfall & -0.001 & 0.008 & 0.006 & 0.012 & 0.011 & 0.032 \\
& $(0.018)$ & $(0.017)$ & $(0.014)$ & $(0.030)$ & $(0.012)$ & $(0.033)$ \\
Trimester 1 - Deficient Rainfall & 0.007 & 0.021 & 0.011 & 0.030 & 0.013 & -0.006 \\
& $(0.027)$ & $(0.022)$ & $(0.018)$ & $(0.018)$ & $(0.016)$ & $(0.032)$ \\
Trimester 2 - Deficient Rainfall & $-0.063^{* * *}$ & -0.015 & $-0.040^{* * *}$ & -0.002 & $-0.038^{* *}$ & 0.002 \\
& $(0.021)$ & $(0.021)$ & $(0.014)$ & $(0.020)$ & $(0.015)$ & $(0.032)$ \\
Trimester 3 - Deficient Rainfall & 0.027 & -0.001 & 0.002 & 0.003 & 0.004 & 0.062 \\
& $(0.020)$ & $(0.013)$ & $(0.017)$ & $(0.021)$ & $(0.010)$ & $(0.046)$ \\
Panel B: Y = Birth Weight in Kilogram & & & & & \\
Trimester 1 - Excessive Rainfall & 0.086 & 0.039 & 0.066 & -0.059 & 0.085 & -0.104 \\
& $(0.079)$ & $(0.062)$ & $(0.054)$ & $(0.069)$ & $(0.071)$ & $(0.114)$ \\
Trimester 2 - Excessive Rainfall & $-0.234^{* * *}$ & -0.048 & $-0.131^{* *}$ & -0.108 & $-0.090^{* *}$ & -0.093 \\
& $(0.072)$ & $(0.054)$ & $(0.064)$ & $(0.094)$ & $(0.044)$ & $(0.145)$ \\
Trimester 3 - Excessive Rainfall & 0.003 & 0.022 & 0.024 & 0.041 & 0.038 & 0.106 \\
& $(0.056)$ & $(0.052)$ & $(0.041)$ & $(0.091)$ & $(0.037)$ & $(0.105)$ \\
Trimester 1 - Deficient Rainfall & 0.022 & 0.061 & 0.035 & 0.084 & 0.037 & -0.024 \\
& $(0.077)$ & $(0.039)$ & $(0.055)$ & $(0.052)$ & $(0.050)$ & $(0.102)$ \\
Trimester 2 - Deficient Rainfall & $-0.186^{* * *}$ & -0.036 & $-0.114^{* *}$ & 0.005 & $-0.106^{* *}$ & 0.031 \\
& $(0.058)$ & $(0.064)$ & $(0.043)$ & $(0.060)$ & $(0.045)$ & $(0.098)$ \\
Observations & 0.076 & 0.012 & 0.012 & 0.030 & 0.018 & 0.194 \\
\hline \hline & $(0.056)$ & $(0.043)$ & $(0.050)$ & $(0.052)$ & $(0.030)$ & $(0.141)$ \\
& 680 & 1,281 & 1,237 & 724 & 1,555 & 406 \\
\hline
\end{tabular}

Note: ${ }^{*} p<0.1,{ }^{* *} p<0.05,{ }^{* * *} p<0.01$. Each column represents coefficients in a separate regression. The column headings indicate the dimensions of heterogeneity. Dependent variables are child's weight at birth in log form (Panel A) and normal form in kilogram (Panel B). All regressions control for district fixed effects, mother characteristics, and child characteristics. Mother characteristics include mother's age at birth, squared age at birth, age at first birth, squared age at first birth, marital status, educational attainment, and wealth level. Child characteristics include child's gender, child's age in months, child's age in months squared, locational status (urban/rural), district-specific birth cohort trend, and conception month-year fixed effects. Robust standard errors are clustered at the district level.

the estimated impacts are comparable to the impacts on children of high education mothers. As for deficient rainfall, we detect more pronounced differences between these two groups with larger effects on children born to low education mothers. Consistent with prior studies on the importance of maternal education on children outcomes (Grytten et al., 2014; Le and 
Nguyen, 2020b), our findings suggest that maternal education could buffer the consequences of adverse events such as deficient rainfall.

\subsection{Robustness Checks}

Child Gender and Teenage Mother - We proceed to examine the robustness of our estimates by imposing several variable and sample restrictions. The results from this exercise are reported in Table 4 where the estimates come from the most extensive specifications. Each of the columns represents a separate regression with the column headings indicating the type of exercise. Columns 1 through 2 report the results for birth weight in log form while Columns 3 through 4 provide the results for birth weight in normal form.

First, several studies suggest that child's gender should not be controlled for in the regression because in-utero exposure to adverse shocks could lead to the decrease of male births (Catalano et al., 2006; Sanders and Stoecker, 2015). Thus, as a robustness check, we remove the child's gender from our regressions. Evident from Columns 1 and 3, the exclusion of the child's gender does not significantly affect our main estimates (compared to Columns 3 and 6 of Table 2). In particular, second-trimester in-utero exposure to excessive and deficient rainfall shocks decreases child's weight at birth by 3.5 and $3.4 \%$ (Column 1) or by 0.098 kilograms respectively (Column 3).

Second, it has been shown that teen pregnancy is linked to poor birth outcomes (Chen et al., 2007; Gibbs et al., 2012), thus leading to a concern that our estimated effects of rainfall shocks are driven by teenage mothers. To address this concern, we exclude teenage mothers and only consider those aged 20 and above when giving birth. As shown in Columns 2 and 4, second-trimester intrauterine exposure to excessive and deficient rainfall shocks is associated with deteriorating birth weight outcomes by 3.5 and $3.2 \%$ (Column 2) or 0.097 and 0.090 kilograms respectively (Column 4). Taken together, Table 4 provides evidence that our estimated impacts of prenatal exposure to rainfall shocks on birth weight are insensitive to different explanatory variable and sample restrictions. 
Table 4: Robustness Checks - Explanatory Variable and Sample Restrictions

\begin{tabular}{|c|c|c|c|c|}
\hline & \multicolumn{2}{|c|}{$Y=\log$ Birth Weight } & \multicolumn{2}{|c|}{$\mathrm{Y}=$ Birth Weight } \\
\hline & $\begin{array}{l}\text { Not Control for } \\
\text { Child's Gender }\end{array}$ & $\begin{array}{l}\text { No Teenage } \\
\text { Mothers }\end{array}$ & $\begin{array}{l}\text { Not Control for } \\
\text { Child's Gender }\end{array}$ & $\begin{array}{c}\text { No Teenage } \\
\text { Mothers }\end{array}$ \\
\hline & (1) & $(2)$ & $(3)$ & $(4)$ \\
\hline Trimester 1 - Excessive Rainfall & $\begin{array}{c}0.015 \\
(0.013)\end{array}$ & $\begin{array}{c}0.011 \\
(0.013)\end{array}$ & $\begin{array}{c}0.051 \\
(0.041)\end{array}$ & $\begin{array}{c}0.038 \\
(0.041)\end{array}$ \\
\hline Trimester 2 - Excessive Rainfall & $\begin{array}{c}-0.035^{* *} \\
(0.015)\end{array}$ & $\begin{array}{c}-0.035^{* *} \\
(0.016)\end{array}$ & $\begin{array}{c}-0.098^{* *} \\
(0.046)\end{array}$ & $\begin{array}{c}-0.097^{* *} \\
(0.047)\end{array}$ \\
\hline Trimester 3 - Excessive Rainfall & $\begin{array}{c}0.007 \\
(0.012)\end{array}$ & $\begin{array}{c}0.009 \\
(0.012)\end{array}$ & $\begin{array}{l}0.025 \\
(0.037)\end{array}$ & $\begin{array}{c}0.032 \\
(0.037)\end{array}$ \\
\hline Trimester 1 - Deficient Rainfall & $\begin{array}{c}0.012 \\
(0.011)\end{array}$ & $\begin{array}{c}0.013 \\
(0.011)\end{array}$ & $\begin{array}{c}0.035 \\
(0.034)\end{array}$ & $\begin{array}{c}0.035 \\
(0.035)\end{array}$ \\
\hline Trimester 2 - Deficient Rainfall & $\begin{array}{c}-0.034^{* *} \\
(0.013)\end{array}$ & $\begin{array}{c}-0.032^{* *} \\
(0.012)\end{array}$ & $\begin{array}{c}-0.098^{* * *} \\
(0.038)\end{array}$ & $\begin{array}{c}-0.090^{* *} \\
(0.037)\end{array}$ \\
\hline Trimester 3 - Deficient Rainfall & $\begin{array}{c}0.004 \\
(0.010)\end{array}$ & $\begin{array}{c}0.005 \\
(0.010)\end{array}$ & $\begin{array}{c}0.019 \\
(0.033)\end{array}$ & $\begin{array}{c}0.023 \\
(0.034)\end{array}$ \\
\hline Observations & 1,961 & 1,900 & 1,961 & 1,900 \\
\hline
\end{tabular}

Note: ${ }^{*} p<0.1,{ }^{* *} p<0.05,{ }^{* * *} p<0.01$. Each column represents coefficients in a separate regression. Dependent variables are the child's weight at birth in log form (Columns 1-2) and normal form in kilogram (Columns 3-4). All regressions control for district fixed effects, mother characteristics, and child characteristics. Mother characteristics include mother's age at birth, age at birth squared, age at first birth, age at first birth squared, marital status, educational attainment, and wealth level. Child characteristics include child's gender, child's age in months, child's age in months squared, locational status (urban/rural), district-specific birth cohort trend, and conception month-year fixed effects. Robust standard errors are clustered at the district level.

Control Group Categorization - Recall that the control group in our main specification includes: (i) mothers subject to rainfall shocks prior to conception, (ii) mothers exposed to rainfall shocks after birth delivery, and (iii) mothers unexposed to rainfall shocks at all. Here, we show in Table 5 that our estimates are robust to different categorizations of the control group suggested by prior studies (Persson and Rossin-Slater, 2018; Matsumoto, 2018; Currie et al., 2019).

First, Currie et al. (2019) suggest that mothers exposed to the adverse shocks right before conception should be a good control group to compare with those exposed during pregnancy. Hence, in Columns 1 and 4, we include only women experiencing rainfall shocks up to 3 months prior to conception as the control group (CG-1). We find that exposure to excessive and deficient rainfall shocks during the second trimester decreases the child's weight at birth 
by 3.7 and $3.4 \%$ (Column 1) or 0.107 and 0.101 kilograms, respectively (Column 4). These estimates are all statistically significant and not much different from the baseline ones.

On the other hand, Persson and Rossin-Slater (2018) and Matsumoto (2018) suggest that the control group should be mothers exposed to adverse shocks just after birth delivery. Therefore, in Columns 2 and 5, we utilize only women experiencing rainfall shocks up to 3 months after delivery as the control group (CG-2). With this restriction, we continue to find statistical evidence for the adverse impacts of second-trimester exposure to rainfall shocks on birth weight. In particular, exposure to excessive and deficient rainfall shocks during the second trimester decreases the child's weight at birth by 4.1 and $3.5 \%$ (Column 2) or 0.116 and 0.102 kilograms respectively (Column 5).

Lastly, we include in our control group mothers exposed to rainfall shocks either three months before conception or three months after giving birth (CG-3). As shown in Columns 3 and 6 , we continue to detect the detrimental impacts of second-trimester exposure to rainfall shocks. The magnitudes are quite comparable to the ones in the baseline (Columns 3 and 6 of Table 2). Quantitatively, exposure to excessive and deficient rainfall shocks during the second trimester of pregnancy decreases the child's weight at birth by 3.8 and $3.5 \%$ (Columns 3) or reduces infant birth weight by 0.107 and 0.101 kilograms (Columns 6) respectively. In sum, our results are robust to various choices of control groups.

\subsection{Discussion}

This paper contributes to the literature by estimating the less apparent cost of rainfall shocks to early human development within the context of Vietnam. The data used in this study come from the Vietnam Multiple Indicator Cluster Survey (MICS) and records for 70 weather stations across Vietnam from the Meteorological and Hydrological Administration of Vietnam. In terms of identification, we employ the difference-in-differences strategy across residential districts and conception months-years to quantify the effects of intrauterine exposure to rainfall shocks on birth weight outcomes. 
Table 5: Robustness Checks - Different Categorizations of Control Group

\begin{tabular}{|c|c|c|c|c|c|c|}
\hline & \multicolumn{3}{|c|}{$\mathrm{Y}=\log$ Birth Weight } & \multicolumn{3}{|c|}{$\mathrm{Y}=$ Birth Weight } \\
\hline & CG-1 & CG-2 & CG-3 & CG-1 & CG-2 & CG-3 \\
\hline & $(1)$ & $(2)$ & (3) & (4) & (5) & $(6)$ \\
\hline Trimester 1 - Excessive Rainfall & $\begin{array}{c}0.013 \\
(0.011)\end{array}$ & $\begin{array}{c}0.014 \\
(0.012)\end{array}$ & $\begin{array}{c}0.015 \\
(0.012)\end{array}$ & $\begin{array}{c}0.041 \\
(0.036)\end{array}$ & $\begin{array}{c}0.046 \\
(0.039)\end{array}$ & $\begin{array}{c}0.049 \\
(0.038)\end{array}$ \\
\hline Trimester 2 - Excessive Rainfall & $\begin{array}{c}-0.037^{* *} \\
(0.017)\end{array}$ & $\begin{array}{c}-0.041^{* *} \\
(0.017)\end{array}$ & $\begin{array}{c}-0.038^{* *} \\
(0.016)\end{array}$ & $\begin{array}{c}-0.107^{* *} \\
(0.051)\end{array}$ & $\begin{array}{c}-0.116^{* *} \\
(0.048)\end{array}$ & $\begin{array}{c}-0.107^{* *} \\
(0.047)\end{array}$ \\
\hline Trimester 3 - Excessive Rainfall & $\begin{array}{c}0.009 \\
(0.013)\end{array}$ & $\begin{array}{c}0.009 \\
(0.013)\end{array}$ & $\begin{array}{c}0.008 \\
(0.013)\end{array}$ & $\begin{array}{c}0.033 \\
(0.039)\end{array}$ & $\begin{array}{c}0.033 \\
(0.040)\end{array}$ & $\begin{array}{c}0.031 \\
(0.039)\end{array}$ \\
\hline Trimester 1 - Deficient Rainfall & $\begin{array}{c}0.007 \\
(0.011)\end{array}$ & $\begin{array}{c}0.011 \\
(0.010)\end{array}$ & $\begin{array}{c}0.010 \\
(0.010)\end{array}$ & $\begin{array}{c}0.015 \\
(0.032)\end{array}$ & $\begin{array}{c}0.029 \\
(0.032)\end{array}$ & $\begin{array}{c}0.028 \\
(0.031)\end{array}$ \\
\hline Trimester 2 - Deficient Rainfall & $\begin{array}{c}-0.034^{* *} \\
(0.014)\end{array}$ & $\begin{array}{c}-0.035^{* * *} \\
(0.013)\end{array}$ & $\begin{array}{c}-0.035^{* * *} \\
(0.013)\end{array}$ & $\begin{array}{c}-0.101^{* *} \\
(0.043)\end{array}$ & $\begin{array}{c}-0.102^{* *} \\
(0.039)\end{array}$ & $\begin{array}{c}-0.101^{* *} \\
(0.040)\end{array}$ \\
\hline Trimester 3 - Deficient Rainfall & $\begin{array}{c}0.003 \\
(0.013)\end{array}$ & $\begin{array}{c}0.002 \\
(0.011)\end{array}$ & $\begin{array}{c}0.003 \\
(0.011)\end{array}$ & $\begin{array}{c}0.014 \\
(0.041)\end{array}$ & $\begin{array}{c}0.013 \\
(0.036)\end{array}$ & $\begin{array}{c}0.017 \\
(0.036)\end{array}$ \\
\hline Observations & 1,468 & 1,457 & 1,578 & 1,468 & 1,457 & 1,578 \\
\hline
\end{tabular}

Note: ${ }^{*} p<0.1,{ }^{* *} p<0.05,{ }^{* * *} p<0.01$. CG-1 denotes control group 1 which consists of mothers exposed to any shocks up to 3 months prior to conception. CG-2 denotes control group 2 which consists of mothers exposed to any shocks up to 3 months after delivery. CG-3 denotes control group 3 which consists of mothers exposed to any shocks 3 months either prior to conception or after delivery. Each column represents coefficients in a separate regression. Dependent variables are the child's weight at birth in log form (Columns 1-3) and normal form in kilogram (Columns 4-6). All regressions control for district fixed effects, mother characteristics, and child characteristics. Mother characteristics include mother's age at birth, age at birth squared, age at first birth, age at first birth squared, marital status, educational attainment, and wealth level. Child characteristics include child's gender, child's age in months, child's age in months squared, locational status (urban/rural), district-specific birth cohort trend, and conception month-year fixed effects. Robust standard errors are clustered at the district level.

Collectively, we uncover harmful impacts of in-utero exposure to rainfall shocks on birth weight outcomes in Vietnam. Specifically, exposure to excessive and deficient rainfall shocks (relative to the long-run local average) during the second trimester of pregnancy decreases the child's weight at birth by $3.5 \%$ (97 grams) and 3.1\% (87 grams) respectively. There is no evidence that intrauterine exposure to rainfall in other trimesters has any effect on child's weight at birth. Our heterogeneity analyses show that infants from poor households seem to be more vulnerable to both excessive and deficient rainfall than those from non-poor households. Besides, deficient rainfall tends to harm infants born to low education mothers and infants from rural areas, whereas the impacts of excessive rainfall do not seem to differ by maternal education or the locational status of infants. The findings underscore the vulnerability to rainfall shocks of children from disadvantaged backgrounds. 
There are multiple mechanisms through which rainfall shocks during gestation could worsen birth weight outcomes. First, adverse rainfall shocks can lower agricultural production and household income, resulting in insufficient food supplies, medical services, vaccine, and vitamin supplement (Bruckner and Ciccone, 2011; Vogel et al., 2019). The lack of nutrition and health inputs during pregnancy is likely to worsen the health outcomes of newborn babies. Second, adverse rainfall shocks might exacerbate both the physical and mental health of pregnant women. Specifically, rainfall shocks could lead to violence against women (Vanden Eynde, 2018; Sekhri and Storeygard, 2014), force women to perform physically demanding tasks (Rao et al., 2003), and make dangerous diseases such as malaria and diarrhea more prevalent (Umbers et al., 2011; Levy et al., 2016). All of these changes induced by rainfall shocks can devastate the physical health of pregnant women. As for mental health, rainfall shocks may engender psychological distress (Obradovich et al., 2018; Cianconi et al., 2020), which could be mentally damaging to pregnant women. The deterioration of both physical health and mental health of pregnant women induced by rainfall shocks is likely to imperil the babies in utero, leading to unfavorable birth outcomes.

Our findings are consistent with closely related studies on the relationship between extreme rainfall and birth outcomes (Simeonova, 2011; Brando and Santos, 2015; Chacón-Montalván et al., 2021). For example, using historical data from the U.S, Simeonova (2011) confirms that maternal exposure to plausibly exogenous excessive rainfall events decreases gestational age and birth weight. Exploiting rainfall shocks caused by La Niña between 2010 and 2011 as a source of variation, Brando and Santos (2015) shows that more days of heavy rain reduce birth weight of Colombian children. Focusing on highly river-dependent areas in Amazonia, Chacón-Montalván et al. (2021) reports that prenatal exposure to excessive and deficient rainfall can lower birth weight by at least 183 and 39 grams, respectively. Moreover, the authors uncover that babies experience penalties totalling 646 grams when born to adolescent.

The findings are also consistent with prior studies on the negative effects of rainfall shocks on the health outcomes of children (Cornwell and Inder, 2015; Dimitrova and Bora, 2020; 
Randell et al., 2020). Specifically, Cornwell and Inder (2015) show that prenatal exposure to rainfall shocks make Indonesian children shorter for their age in early childhood. According to Dimitrova and Bora (2020), in-utero exposure to excessive rainfall raises the risk of stunting among Indian children via the elevation of diseases transmitted through water. Similarly, Randell et al. (2020) find that higher rainfall during gestation leads to height deficit among Ethiopian children. The adverse relationship between in-utero rainfall and child weight and height is also detected in Le and Nguyen (2021) for developing countries. As for exposure timing, while Randell et al. (2020) highlight the relative importance of the third trimester, Le and Nguyen (2021) find that the impacts of in-utero rainfall are almost equally spread in all three trimesters.

Moreover, our findings are also consonant with studies emphasizing the injurious consequence of in-utero shocks on birth outcomes. In particular, in-utero exposure to high temperature is reported to decrease birth weight (Deschenes et al., 2009; Molina and Saldarriaga, 2017). Experiencing air pollution, discrimination, armed conflict, or uprising during gestation has also been found to adversely affect child's weight at birth (Earnshaw et al. 2013; Lee, 2014; Severnini, 2015; Le and Nguyen, 2020a). Furthermore, children prenatally exposed to disasters like hurricane and earthquake also tend to weigh less at birth (Oyarzo et al., 2012; Fuller, 2013; Liu et al., 2015; Beuermann and Camilo, 2020; de Oliveira et al., 2021). In-utero exposure to other shocks such as nutritional deprivation, power outage, and pandemic can also result in lower birth weight (Almond and Mazumder, 2011; Burlando, 2014; Savitri et al. 2014; Pathirathna et al., 2017).

Regarding the relative importance of exposure timing, our findings that the consequences of in-utero exposure to rainfall shocks are concentrated in the second trimester of pregnancy are in line with several closely related studies. For example, excessive rainfall during the second trimester reduces birth weight by 18 grams in the U.S and 112 grams in Colombia (Simeonova, 2011; Brando and Santos, 2015). Compared to these magnitudes, ours are closer to the one found in the context of Colombia. The smaller impact in the U.S may due to its 
sophisticated infrastructure and healthcare system to effectively mitigate adverse shocks.

Table 6: Results from Related Studies

\begin{tabular}{lccll}
\hline Events & Trimester & Effects & Country & Study \\
\hline Panel A: Extreme Rainfall and Birth Weight & \\
Excessive rainfall & 2 & $\downarrow 97 \mathrm{~g}$ & Vietnam & This study \\
Deficient rainfall & 2 & $\downarrow 87 \mathrm{~g}$ & Vietnam & This study \\
Excessive rainfall & - & $\downarrow 183 \mathrm{~g}$ & Brazil & Chacón-Montalván et al. (2021) \\
Deficient rainfall & - & $\downarrow 39 \mathrm{~g}$ & Brazil & Chacón-Montalván et al. (2021) \\
Excessive rainfall & 1 & $\downarrow 101 \mathrm{~g}$ & Colombia & Brando \& Santos (2015) \\
Excessive rainfall & 2 & $\downarrow 112 \mathrm{~g}$ & Colombia & Brando \& Santos (2015) \\
Excessive rainfall & 2 & $\downarrow 18 \mathrm{~g}$ & United States & Simeonova (2011) \\
& & & & \\
Panel B: Other Events and Birth & Weight & & \\
Hurricane & 2 & $\downarrow 92 \mathrm{~g}$ & United States & Fuller (2013) \\
Hurricane & 3 & $\downarrow 880 \mathrm{~g}$ & Jamaica & Beuermann \& Camilo (2020) \\
Hurricane & - & $\downarrow 44 \mathrm{~g}$ & Brazil & de Oliveira et al. (2021) \\
Earthquake & 2 & $\downarrow 25 \mathrm{~g}$ & Taiwan & Liu et al. (2015) \\
Earthquake & 1 & $\downarrow 86 \mathrm{~g}$ & Chile & Oyarzo et al. (2012) \\
Temperature shock & 1 & $\downarrow 43 \mathrm{~g}$ & Andean states & Molina \& Saldarriaga (2017) \\
1 extreme heat day & 2 & $\downarrow 2.4-5.1 \mathrm{~g}$ & United States & Deschenes et al. (2009) \\
1 extreme heat day & 3 & $\downarrow 3.1-5.1 \mathrm{~g}$ & United States & Deschenes et al. (2009) \\
Discrimination & 2 & $\downarrow 49 \mathrm{~g}$ & United States & Earnshaw et al. (2013) \\
Uprising & 2 & $\downarrow 103 \mathrm{~g}$ & South Korea & Lee (2014) \\
Power outage & 1 & $\downarrow 47 \mathrm{~g}$ & Tanzania & Burlando (2014) \\
Power plant pollution & 2 & $\downarrow 97 \mathrm{~g}$ & United States & Severnini (2015) \\
Power plant pollution & 3 & $\downarrow 146 \mathrm{~g}$ & United States & Severnini (2015) \\
Low carbohydrate intake & 2 & $\downarrow 312 \mathrm{~g}$ & Sri Lanka & Pathirathna et al. (2017) \\
Fasting period & 1 & $\downarrow 20 \mathrm{~g}$ & United States & Almond \& Mazumder (2011) \\
Fasting period & $\downarrow 25 \mathrm{~g}$ & United States & Almond \& Mazumder (2011) \\
Fasting period & $\downarrow 272 \mathrm{~g}$ & Netherlands & Savitri et al. (2014) \\
\hline \hline
\end{tabular}

Note: "-" indicates that the timing of exposure is not reported in the study

The findings on exposure timing are also consistent with studies emphasizing other types of in-utero shocks. Specifically, being prenatally exposed to natural disasters such as hurricane and earthquake during the second trimester leads African American infants and Taiwanese male infants to weigh 92 and 25 grams less at birth, respectively (Fuller, 2013; Liu et al., 
2015). Deschenes et al. (2009) also find that one additional day of extreme heat during the second trimester reduces birth weight of American infants by 2.4-5.1 grams. In addition to natural events, being prenatally exposed to man-made events like discrimination and uprising during the second trimester leads American minority and Korean infants to weigh 49 and 103 grams less at birth, respectively (Earnshaw et al., 2013; Severnini, 2015). Experiencing pollution from power plants during the second trimester is also reported to be associated with a 97 gram reduction in American birth weight (Earnshaw et al. 2013). Furthermore, according to Almond and Mazumder (2011) and Pathirathna et al. (2017), exposure to nutritional deprivation due to mother fasting and low carbohydrate intake during the second trimester reduces birth weight by 25.3 grams in the U.S and 312 grams in Sri Lanka. To facilitate the discussion, Table 6 provides the comparison of findings between our study and those of prior studies.

Being regarded as a global threat, climate change is projected to affect nearly all regions in the world and Vietnam is of course not an exception. With total annual rainfall being projected to rise throughout the country, Vietnam is especially vulnerable to the changes in climatic indicators such as rainfall (FAO, 2011). Our study underlines the detrimental ramifications of rainfall shocks on early human capital formation in Vietnam. Because the adverse impacts of poor infant health could persist to adulthood such as lower educational attainment, declining labor productivity, worsening labor market outcome, and increased vulnerability to diseases (Reyes and Manalich, 2005; Black et al., 2007; Oreopoulos et al., 2008; Xie et al., 2019), the cost of rainfall shocks to long-term human development might be larger than previously estimated. Therefore, our study calls for measures to minimize the impacts of rainfall shocks. Government interventions that seek to protect pregnant women from the threat of climatic events are justified. Extra attention should be given to children born to poor, rural, and low education mothers since these are the most vulnerable groups. 


\section{References}

Hobel, C. J., Dunkel-Schetter, C., Roesch, S. C., Castro, L. C., \& Arora, C. P. (1999). Maternal plasma corticotropin-releasing hormone associated with stress at 20 weeks' gestation in pregnancies ending in preterm delivery. American Journal of Obstetrics and Gynecology, 180(1), S257-S263.

Sherrieb, K., \& Norris, F. H. (2013). Public health consequences of terrorism on maternal-child health in New York City and Madrid. Journal of Urban Health, 90(3), 369-387.

Umbers, A. J., Aitken, E. H., \& Rogerson, S. J. (2011). Malaria in pregnancy: small babies, big problem. Trends in Parasitology, 27(4), 168-175.

Le, K., \& Nguyen, M. (2020). Armed conflict and birth weight. Economics \& Human Biology, 39, 100921.

Levy, K., Woster, A. P., Goldstein, R. S., \& Carlton, E. J. (2016). Untangling the impacts of climate change on waterborne diseases: a systematic review of relationships between diarrheal diseases and temperature, rainfall, flooding, and drought. Environmental Science \& Technology, 50(10), 4905-4922.

Myhre, G., Alterskjær, K., Stjern, C. W., Hodnebrog, Ø., Marelle, L., Samset, B. H., ... \& Stohl, A. (2019). Frequency of extreme precipitation increases extensively with event rareness under global warming. Scientific Reports, 9(1), 1-10.

Alexander, L. V. (2016). Global observed long-term changes in temperature and precipitation extremes: a review of progress and limitations in IPCC assessments and beyond. Weather and Climate Extremes, $11,4-16$.

Guendelman, S., Lang Kosa, J., Pearl, M., Graham, S., \& Kharrazi, M. (2008). Exploring the relationship of second-trimester corticotropin releasing hormone, chronic stress and preterm delivery. The Journal of Maternal-Fetal \& Neonatal Medicine, 21(11), 788-795.

Le, K., \& Nguyen, M. (2020). Shedding light on maternal education and child health in developing countries. World Development, 133, 105005.

Hidalgo, F. D., Naidu, S., Nichter, S., \& Richardson, N. (2010). Economic determinants of land invasions. The Review of Economics and Statistics, 92(3), 505-523.

Lunney, L. H. (1998). Compensatory placental growth after restricted maternal nutrition in early pregnancy. Placenta, 19(1), 105-111.

Matsumoto, B. (2018). Family ruptures, stress, and the mental health of the next generation: comment. American Economic Review, 108(4-5), 1253-55.

Schneider, M. L., Roughton, E. C., Koehler, A. J., \& Lubach, G. R. (1999). Growth and development following prenatal stress exposure in primates: an examination of ontogenetic vulnerability. Child Development, $70(2), 263-274$.

United Nations Children's Fund (UNICEF). (2014). Multi-sectoral approaches to nutrition: nutritionspecific and nutritionsensitive interventions to accelerate progress. UNICEF, New York.

Corman, H., Joyce, T. J., \& Grossman, M. (1987). Birth outcome production function in the United States. Journal of Human Resources, 339-360.

Le, K. (2021). Armed Conflict and Child Weight in DR Congo. Advances in Public Health, 2021.

Gibbs, C. M., Wendt, A., Peters, S., \& Hogue, C. J. (2012). The impact of early age at first childbirth on maternal and infant health. Paediatric and Perinatal Epidemiology, 26, 259-284.

Reyes, L., \& Manalich, R. (2005). Long-term consequences of low birth weight. Kidney International, 68, S107-S111.

Van den Bergh, B. R., Mulder, E. J., Mennes, M., \& Glover, V. (2005). Antenatal maternal anxiety and stress and the neurobehavioural development of the fetus and child: links and possible mechanisms. A review. Neuroscience \&3 Biobehavioral Reviews, 29(2), 237-258. 
Black, S. E., Devereux, P. J., \& Salvanes, K. G. (2007). From the cradle to the labor market? The effect of birth weight on adult outcomes. The Quarterly Journal of Economics, 122(1), 409-439.

Rao, S., Kanade, A., Margetts, B. M., Yajnik, C. S., Lubree, H., Rege, S., ... \& Fall, C. H. (2003). Maternal activity in relation to birth size in rural India. The Pune Maternal Nutrition Study. European Journal of Clinical Nutrition, 57(4), 531-542.

Le, K. (2020). Land use restrictions, misallocation in agriculture, and aggregate productivity in Vietnam. Journal of Development Economics, 145, 102465.

Bruckner, M., \& Ciccone, A. (2011). Rain and the democratic window of opportunity. Econometrica, $79(3), 923-947$.

Field, T., \& Diego, M. (2008). Cortisol: the culprit prenatal stress variable. International Journal of Neuroscience, 118(8), 1181-1205.

Oreopoulos, P., Stabile, M., Walld, R., \& Roos, L. L. (2008). Short-, medium-, and long-term consequences of poor infant health an analysis using siblings and twin

Le, K., \& Nguyen, M. (2021). In-utero Exposure to Rainfall Variability and Early Childhood Health. World Development, 144, 105485.

Catalano, R., Bruckner, T., Marks, A. R., \& Eskenazi, B. (2006). Exogenous shocks to the human sex ratio: the case of September 11, 2001 in New York City. Human Reproduction, 21(12), 3127-3131.

Chen, X. K., Wen, S. W., Fleming, N., Demissie, K., Rhoads, G. G., \& Walker, M. (2007). Teenage pregnancy and adverse birth outcomes: a large population based retrospective cohort study. International Journal of Epidemiology, 36(2), 368-373.

Field, T., Diego, M., \& Hernandez-Reif, M. (2006). Prenatal depression effects on the fetus and newborn: a review. Infant Behavior and Development, 29(3), 445-455.s. Journal of Human Resources, 43(1), 88-138.

Persson, P., \& Rossin-Slater, M. (2018). Family ruptures, stress, and the mental health of the next generation. American Economic Review, 108(4-5), 1214-52.

Le, K., \& Nguyen, M. (2021). The Impacts of Temperature Shocks on Birth Weight in Vietnam. Population and Development Review.

Food and Agriculture Organization (FAO). (2011). Climate Change Impacts on Agriculture in Vietnam. FAO, Hanoi. Available at http://www.fao.org/climatechange/340880de07b3e1fa7a69d37efc90a2fa39b34d.pdf

Miguel, E., Satyanath, S., \& Sergenti, E. (2004). Economic shocks and civil conflict: An instrumental variables approach. Journal of Political Economy, 112(4), 725-753.

Le, K., \& Nguyen, M. (2021). Education and political engagement. International Journal of Educational Development, 85, 102441.

Xie, L. F., Alos, N., Cloutier, A., Béland, C., Dubois, J., Nuyt, A. M., \& Luu, T. M. (2019). The long-term impact of very preterm birth on adult bone mineral density. Bone Reports, 10, 100189.

Obradovich, N., Migliorini, R., Paulus, M. P., \& Rahwan, I. (2018). Empirical evidence of mental health risks posed by climate change. Proceedings of the National Academy of Sciences, 115 (43), 10953-10958.

Cianconi, P., Betro, S., \& Janiri, L. (2020). The impact of climate change on mental health: a systematic descriptive review. Frontiers in Psychiatry, 11. birth. Journal of Health Economics, 56, 47-60.

Le, K., \& Nguyen, M. (2020). The impacts of farmland expropriation on Vietnam's rural households. Review of Development Economics, 24(4), 1560-1582.

Quintana-Domeque, C., \& Rodenas-Serrano, P. (2017). The hidden costs of terrorism: The effects on health at

Vogel, E., Donat, M. G., Alexander, L. V., Meinshausen, M., Ray, D. K., Karoly, D., ... \& Frieler, K. (2019). The effects of climate extremes on global agricultural yields. Environmental Research Letters, $14(5), 054010$. 


\section{Appendix}

Table A1: Correlation Test: Weight from Card and Children Variables

\begin{tabular}{lccccc}
\hline & $\begin{array}{c}\text { Birth } \\
\text { Weight }(\mathrm{kg})\end{array}$ & $\begin{array}{c}\text { Log Birth } \\
\text { Weight }\end{array}$ & $\begin{array}{c}\text { Being } \\
\text { Male }\end{array}$ & $\begin{array}{c}\text { Age in } \\
\text { Month }\end{array}$ & $\begin{array}{c}\text { Residing in } \\
\text { Urban Area }\end{array}$ \\
\cline { 2 - 6 } & $(1)$ & $(2)$ & $(3)$ & $(4)$ & $(5)$ \\
\hline Panel A: Without Remaining Covariates & & & \\
Weight from Card & -0.053 & -0.019 & 0.012 & -0.402 & 0.010 \\
Observations & $(0.039)$ & $(0.014)$ & $(0.040)$ & $(0.308)$ & $(0.030)$ \\
Panel B: With Remaining Covariates & & 1,961 & 1,961 & 1,961 \\
Weight from Card & -0.043 & -0.018 & 0.010 & -0.017 & -0.002 \\
Observations & $(0.038)$ & $(0.013)$ & $(0.043)$ & $(0.064)$ & $(0.026)$ \\
\hline \hline
\end{tabular}

Note: ${ }^{*} p<0.1,{ }^{* *} p<0.05,{ }^{* * *} p<0.01$. In each panel, each column is a separate regression. The column heading indicates the outcome variables. In Panel A, there is no control variable except the Weight from Card indicator. In Panel B, regressions control for district and conception month-year fixed effects, district-specific birth cohort trend, as well as child and mother characteristics. Regressions in Column 3 through 5 exclude the characteristics which are already the outcome variables. Robust standard errors are clustered at the district level.

Table A2: Correlation Test: Weight from Card and Mother Variables

\begin{tabular}{lccccc}
\hline & $\begin{array}{c}\text { Age at } \\
\text { Birth }\end{array}$ & $\begin{array}{c}\text { Age at } \\
\text { First Birth }\end{array}$ & $\begin{array}{c}\text { Currently } \\
\text { Married }\end{array}$ & $\begin{array}{c}\text { High School } \\
\text { Graduate }\end{array}$ & $\begin{array}{c}\text { Wealth } \\
\text { Index }\end{array}$ \\
\cline { 2 - 6 } & $(1)$ & $(2)$ & $(3)$ & $(4)$ & $(5)$ \\
\hline \multicolumn{7}{l}{ Panel A: Without Remaining Covariates } & & & \\
Weight from Card & -0.538 & 0.074 & 0.002 & -0.003 & 0.049 \\
Observations & $(0.452)$ & $(0.293)$ & $(0.009)$ & $(0.025)$ & $(0.130)$ \\
Panel B: With Remaining Covariates & 1,961 & 1,961 & 1,961 & 1,961 & 1,961 \\
Weight from Card & -0.527 & 0.180 & 0.002 & -0.017 & -0.041 \\
\multicolumn{7}{l}{ Observations } & $(0.400)$ & $(0.238)$ & $(0.008)$ & $(0.028)$ & $(0.102)$ \\
\hline \hline
\end{tabular}

Note: ${ }^{*} p<0.1,{ }^{* *} p<0.05,{ }^{* * *} p<0.01$. In each panel, each column is a separate regression. The column heading indicates the outcome variables. In Panel A, there is no control variable except the Weight from Card indicator. In Panel B, regressions control for district and conception month-year fixed effects, district-specific birth cohort trend, as well as child and mother characteristics. Regressions in Column 3 through 5 exclude the characteristics which are already the outcome variables. Robust standard errors are clustered at the district level. 
Figure A1: Geographic Distribution of Districts and Rainfall Stations

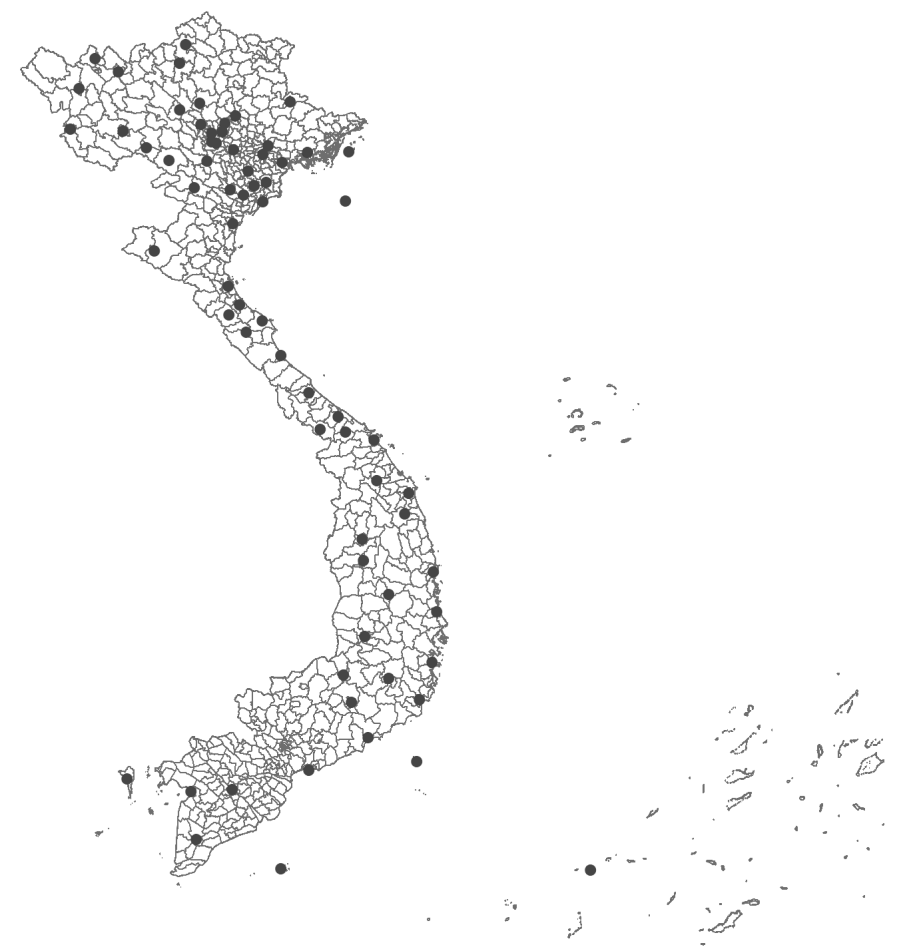

Note: Gray polygons and black dots illustrate district boundaries and rainfall stations, respectively 